Pacific Journal of Mathematics

ON A SPLITTING FIELD OF REPRESENTATIONS OF A FINITE 


\title{
ON A SPLITTING FIELD OF REPRESENTATIONS OF A FINITE GROUP
}

\author{
TOSHIHIKo YAMADA
}

\begin{abstract}
The theorem of $P$. Fong about a splitting field of representations of a finite group $G$ will be improved to the effect that the order of $G$ mentioned in it will be replaced by the exponent of $G$. The proof depends on the Brauer-Witt theorem and properties of cyclotomic algebras.
\end{abstract}

Let $Q$ denote the rational field. For a positive integer $n, \zeta_{n}$ is a primitive $n$th root of unity. Let $\chi$ be an irreducible character of a finite group $G$ (an irreducible character means an absolutely irreducible one). Let $K$ be a field of characteristic 0 . Then $m_{K}(\chi)$ denotes the Schur index of $\chi$ over $K$. The simple component of the group algebra $K[G]$ corresponding to $\chi$ is denoted by $A(\chi, K)$. Its index is exactly $m_{K}(\chi)$. If $L / K$ is normal, $\mathscr{G}(L / K)$ is the Galois group of $L$ over $K$.

In this paper we will prove the following:

THEOREM. Let $G$ be a finite group of exponent $s=l^{a} n$, where $l$ is a rational prime and $(l, n)=1$. Let $k=Q\left(\zeta_{n}\right)$ if $l$ is odd, let $k=Q\left(\zeta_{n}, \zeta_{4}\right)$ if $l=2$. Then, $m_{k}(\chi)=1$ for every irreducible character $\chi$ of $G$.

REMARK. In Fong [2, Theorem 1], the above $s$ denoted the order of $G$ (instead of the exponent of $G$ ).

First we review

BraUer-WitT THEOREM. Let $\chi$ be an irreducible character of a finite group $G$ of exponent $s$. Let $q$ be a prime number. Let $K$ be a field of characteristic 0 with $K(\chi)=K$. Let $L$ be the subfield of $K\left(\zeta_{s}\right)$ over $K$ such that $\left[K\left(\zeta_{s}\right): L\right]$ is a power of $q$ and $[L: K] \not \equiv 0$ $(\bmod q)$. Then there is a subgroup $F$ of $G$ and an irreducible character $\xi$ of $F$ with the following properties: (1) there is a normal subgroup $N$ of $F$ and a linear character $\psi$ of $N$ such that $\xi=\psi^{F}$ and $L(\xi)=L$, (2) $F / N \cong \mathscr{G}(L(\psi) / L)$, (3) $m_{L}(\xi)$ is equal to the q-part of $m_{R}(\chi)$, (4) for every $f \in F$ there is a $\tau(f) \in \mathscr{G}(L(\psi) / L)$ such that $\psi\left(f n f^{-1}\right)=\tau(f)(\psi(n))$ for all $n \in N$, and (5) $A(\xi, L)$ is isomorphic to the crossed product $(\beta, L(\psi) / L)$ where, if $S$ is a complete set of coset representatives of $N$ in $F(1 \in S)$ with $f f^{\prime}=n\left(f, f^{\prime}\right) f^{\prime \prime}$ for $f, f^{\prime}, f^{\prime \prime} \in S$, $n\left(f, f^{\prime}\right) \in N$, then $\beta\left(\tau(f), \tau\left(f^{\prime}\right)\right)=\psi\left(n\left(f, f^{\prime}\right)\right)$. 
Proof. See, for instance, [1] and [4].

REMARK. The above crossed product is called a cyclotomic algebra (cf. [3]).

Corollary. Let $p$ be a prime number. Denote by $Q_{p}$ the rational $p$-adic field. Suppose that $p \nmid s$ if $p \neq 2$, and that $4 \nmid s$ if $p=2, s$ being the exponent of $G$. Then $m_{Q_{p}}(\chi)=1$ for every irreducible character $\chi$ of $G$.

Proof. Set $K=Q_{p}(\chi)$. Then $m_{K}(\chi)=m_{Q_{p}}(\chi)$. Let $q$ be any prime number. By the Brauer-Witt theorem, the $q$-part of $m_{K}(\chi)$ equals the index of some cyclotomic algebra of the form $(\beta, L(\psi) / L)$, where $Q_{p} \subset K \subset L \subset L(\psi) \subset Q_{p}\left(\zeta_{s}\right)$. It follows from the assumption that the extension $Q_{p}\left(\zeta_{s}\right) / Q_{p}$ is unramified, a fortiori, $L(\psi) / L$ is unramified. Because the values of the factor set $\beta$ are roots of unity, it follows that $(\beta, L(\psi) / L) \sim L$. As $q$ is an arbitrary prime, we conclude that $m_{K}(\chi)=1$.

For the remainder of the paper we will use the same notation as in the theorem. Recall that $m_{k}(\chi)$ is the index of $A(\chi, k(\chi))$. Hence it suffices to prove $A(\chi, k(\chi)) \boldsymbol{\otimes}_{k(x)} k(\chi)_{\mathfrak{p}} \sim k(\chi)_{\mathfrak{p}}$ for every prime $\mathfrak{p}$ of $k(\chi)$, where $k(\chi)_{p}$ is the completion of $k(\chi)$ with respect to $\mathfrak{p}$. For simplicity, set $K=k(\chi)_{\mathfrak{p}}$. Because $A(\chi, k(\chi)) \bigotimes_{k(\chi)} K$ is $K$-isomorphic to $A(\chi, K)$, we need to show $A(\chi, K) \sim K$, i.e., $m_{K}(\chi)=1$. Note that $k(\chi)$ is a cyclotomic extension of the rational field $Q$. If $M$ is a cyclotomic extension of $Q$ containing $k(\chi)$, then $M^{\vee}$ represents the isomorphy type of the completion $M_{\mathfrak{*}}$, $\mathfrak{\beta}$ being any prime of $M$ dividing $\mathfrak{p}$.

(i) Suppose that $\mathfrak{p}$ is an infinite prime. Denote by $R$ (resp. $C$ ) the field of real numbers (resp. complex numbers). If $k(\chi)$ is not real, then $\mathfrak{p}$ is a complex prime, and so $m_{K}(\chi)=1$. Suppose that $k(\chi)$ is real. Then $K=k(\chi)_{p}=R, l \neq 2$, and $n=1$ or 2, i.e., $k=Q\left(\zeta_{n}\right)=$ $Q$ and $\chi$ is real valued. Therefore, 4 does not divide $s$, the exponent of $G$. If $s=1$ or 2 , then $G$ is abelian, and so $m_{k}(\chi)=1$. Hence we assume that $s>2$, so that the field $Q\left(\zeta_{s}\right)$ is imaginary and $R=K \subset$ $Q\left(\zeta_{s}\right)^{p}=C$. Note that $m_{K}(\chi)=1$ or 2. By the Brauer-Witt theorem there are subgroups $F$ and $N$ of $G$ and a linear character $\psi$ of $N$ such that $F \triangleright N$ and $R\left(\psi^{F}\right)=R(\chi)=R$ and that $m_{R}(\chi)$ is equal to the index of a cyclotomic algebra of the form $(\beta, R(\psi) / R)$. Recall that $\mathscr{G}(R(\psi) / R) \cong F / N$. If $R(\psi)=R$, then $(\beta, R(\psi) / R) \sim R$. If $R(\psi)=$ $C$, then $[F: N]=2$. Set $F=N \cup N f$. We have

$$
(\beta, R(\psi) / R)=\left(\psi\left(f^{2}\right), C / R, \rho\right), \quad(\rho(\sqrt{-1})=-\sqrt{-1})
$$


where the right side denotes a cyclic algebra over $R$ and $\psi\left(f^{2}\right)$ is a root of unity contained in $R$ so that $\psi\left(f^{2}\right)= \pm 1$. If $\psi\left(f^{2}\right)=-1$, then the order of $f$ would be divisible by 4 , which is a contradiction. Consequently, $\psi\left(f^{2}\right)=1$ and so $\left(\psi\left(f^{2}\right), C / R, \rho\right) \sim R$, yielding that $m_{K}(\chi)=1$.

(ii) Suppose that $\mathfrak{p}$ does not divide $s=l^{a} n$. Then the corollary implies that $m_{K}(\chi)=1$.

(iii) Suppose that $\mathfrak{p} \mid l$ and $l=2$. Then $\zeta_{4} \in k$, and so $\zeta_{4} \in K$. It follows from [3, Satz 12] that $m_{K}(\chi)=1$.

(iv) Suppose that $\mathfrak{p} \mid l$ and $l \neq 2$. Let $q$ be a prime number. Let $L$ be the subfield of $M=Q\left(\zeta_{l a}, \zeta_{n}\right)^{p}$ over $K=k(\chi)_{p}=Q\left(\zeta_{n}, \chi\right)_{p}$ such that $q \nmid[L: K]$ and $[M: L]$ is a power of $q$. By the Brauer-Witt theorem there exist subgroups $F$ and $N$ of $G$ and a linear character $\psi$ of $N$ such that $G \supset F \triangleright N, \mathscr{G}(L(\psi) / L) \cong F / N,[F: N]$ is a power of $q$, and the $q$-part of $m_{K}(\chi)$ is equal to the index of a cyclotomic algebra of the form $(\beta, L(\psi) / L)$. Since $l \neq 2$ and $\mathscr{G}(M / K)$ is canonically isomorphic to a subgroup of $\mathscr{G}\left(Q\left(\zeta_{l}\right) / Q\right)$, it follows that $M / K$ is cyclic, and so $L(\psi) / L$ is cyclic. Let $q^{c}=[F: N]=[L(\psi): L],\langle\sigma\rangle=\mathscr{G}(L(\psi) / L)$ and $F=\bigcup_{i=0}^{q^{c-1}} N f^{i}$. Then we have

$$
(\beta, L(\psi) / L)=\left(\psi\left(f^{q^{c}}\right), L(\psi) / L, \sigma\right), \quad \psi\left(f^{q^{c}}\right) \in L .
$$

As $\psi$ is a linear character, $\psi\left(f^{q^{c}}\right)$ is a primitive $t$ th root of unity for some integer $t$. Let $t=q^{d} h,(q, h)=1$. Then we can write $\psi\left(f^{q^{c}}\right)=$ $\zeta_{q^{d}} \zeta_{h}$, which implies that the order of $f$ is divisible by $q^{c+d}$. Consequently, $q^{c+d}$ divides $n$, and so a primitive $q^{c+d}$ th root of unity $\zeta_{q^{c+d}}$ belongs to $L$. We may assume that $\zeta_{q^{c+d}}^{q^{c}}=\zeta_{q d}$. Let $r$ be an integer satisfying $r q^{c} \equiv 1(\bmod h)$. Since both $\zeta_{q c+d}$ and $\zeta_{h}$ belong to $L$, it follows that

$$
N_{L(\psi) / L}\left(\zeta_{q^{c+d}} \zeta_{h}^{r}\right)=\zeta_{q^{c+d}}^{q^{c}} \zeta_{h}^{r q^{c}}=\zeta_{q^{d}} \zeta_{h},
$$

which yields that $\left(\psi\left(f^{q^{c}}\right), L(\psi) / L, \sigma\right) \sim L$. Therefore, the $q$-part of $m_{K}(\chi)$ is equal to 1 . As $q$ is an arbitrary prime, it follows that $m_{K}(\chi)=1$.

(v) Suppose that $\mathfrak{p} \mid n$ and $\mathfrak{p} \nmid 2$. Then $k$ contains a primitive $p$ th root of unity $\zeta_{p}, p$ being the rational prime divided by $\mathfrak{p}$. It follows from [3, Satz 12] that $m_{K}(\chi)=1$.

(vi) Suppose that $\mathfrak{p} \mid n$ and $\mathfrak{p} \mid 2$. Then $k=Q\left(\zeta_{n}\right)$. If $4 \mid n$ then $\zeta_{4} \in K$ and so $m_{K}(\chi)=1$. If $4 \nmid n$, then $4 \nmid s$. It follows from the corollary that $m_{K}(\chi)=1$.

The theorem is completely proved.

\section{REFERENCES}

1. W. Feit, Characters of Finite Groups, Benjamin, New York, 1967. 
2. P. Fong, A note on splitting fields of representations of finite groups, Illinois J. Math., 7 (1963), 515-520.

3. E. Witt, Die algebraische Struktur des Gruppenringes einer endlichen Gruppe über einem Zahlkörper, J. Reine Angew. Math., 190 (1952), 231-245.

4. T. Yamada, Characterization of the simple components of the group algebras over the p-adic number field, J. Math. Soc. Japan, 23 (1971), 295-310.

Received February 21, 1973. This research was done while the author was a Visiting Associate Professor of Queen's University for 1971/72.

TOKyo Metropolitan UNIVERSity 


\section{PACIFIC JOURNAL OF MATHEMATICS}

\section{EDITORS}

RICHARD ARENS (Managing Editor)

University of California

Los Angeles, California 90024
J. DUGUNDJI*

Department of Mathematics

University of Southern California

Los Angeles, California 90007

D. Gilbarg and J. Milgram

Stanford University

Stanford, California 94305
University of Washington

Seattle, Washington 98105

ASSOCIATE EDITORS
E. F. BECKENBACH
B. H. NeumanN
F. WoLF
K. YosHIDA

\section{SUPPORTING INSTITUTIONS}

\author{
UNIVERSITY OF BRITISH COLUMBIA \\ CALIFORNIA INSTITUTE OF TECHNOLOGY \\ UNIVERSITY OF CALIFORNIA \\ MONTANA STATE UNIVERSITY \\ UNIVERSITY OF NEVADA \\ NEW MEXICO STATE UNIVERSITY \\ OREGON STATE UNIVERSITY \\ UNIVERSITY OF OREGON \\ OSAKA UNIVERSITY
}

\author{
UNIVERSITY OF SOUTHERN CALIFORNIA \\ STANFORD UNIVERSITY \\ UNIVERSITY OF TOKYO \\ UNIVERSITY OF UTAH \\ WASHINGTON STATE UNIVERSITY \\ UNIVERSITY OF WASHINGTON
* * * *
AMERICAN MATHEMATICAL SOCIETY \\ NAVAL WEAPONS CENTER
}

The Supporting Institutions listed above contribute to the cost of publication of this Journal, but they are not owners or publishers and have no responsibility for its content or policies.

Mathematical papers intended for publication in the Pacific Journal of Mathematics should be in typed form or offset-reproduced, (not dittoed), double spaced with large margins. Underline Greek letters in red, German in green, and script in blue. The first paragraph or two must be capable of being used separately as a synopsis of the entire paper. Items of the bibliography should not be cited there unless absolutely necessary, in which case they must be identified by author and Journal, rather than by item number. Manuscripts, in duplicate if possible, may be sent to any one of the four editors. Please classify according to the scheme of Math. Rev. Index to Vol. 39. All other communications to the editors should be addressed to the managing editor, or Elaine Barth, University of California, Los Angeles, California, 90024.

100 reprints are provided free for each article, only if page charges have been substantially paid. Additional copies may be obtained at cost in multiples of 50 .

The Pacific of Journal Mathematics is issued monthly as of January 1966. Regular subscription rate: $\$ 72.00$ a year (6 Vols., 12 issues). Special rate: $\$ 36.00$ a year to individual members of supporting institutions.

Subscriptions, orders for back numbers, and changes of address should be sent to Pacific Journal of Mathematics, 103 Highland Boulevard, Berkeley, California, 94708.

PUBLISHED BY PACIFIC JOURNAL OF MATHEMATICS, A NON-PROFIT CORPORATION

Printed at Kokusai Bunken Insatsusha (International Academic Printing Co., Ltd.), 270, 3-chome Totsuka-cho, Shinjuku-ku, Tokyo 160, Japan.

* C. R. DePrima California Institute of Technology, Pasadena, CA 91109, will replace J. Dugundji until August 1974.

Copyright (C) 1973 by Pacific Journal of Mathematics

Manufactured and first issued in Japan 


\section{Pacific Journal of Mathematics}

\section{Vol. 51, No. $2 \quad$ December, 1974}

Robert F. V. Anderson, Laplace transform methods in multivariate spectral theory .................................................. 339

William George Bade, Two properties of the Sorgenfrey plane . . . . . . . . . . . . 349

John Robert Baxter and Rafael Van Severen Chacon, Functionals on continuous

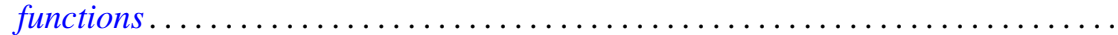

Phillip Wayne Bean, Helly and Radon-type theorems in interval convexity

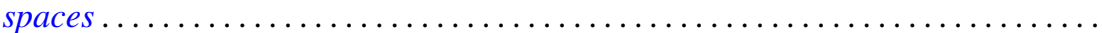

James Robert Boone, On k-quotient mappings $\ldots \ldots \ldots \ldots \ldots \ldots \ldots \ldots \ldots$

Ronald P. Brown, Extended prime spots and quadratic forms . . . . . . . . . . . .

William Hugh Cornish, Crawley's completion of a conditionally upper continuous lattice .............................................

Robert S. Cunningham, On finite left localizations ...................

Robert Jay Daverman, Approximating polyhedra in codimension one spheres

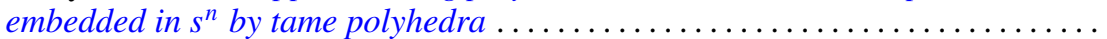

Burton I. Fein, Minimal splitting fields for group representations . . . . . . . . . . . .

Peter Fletcher and Robert Allen McCoy, Conditions under which a connected

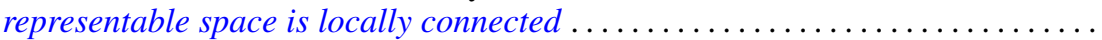

Jonathan Samuel Golan, Topologies on the torsion-theoretic spectrum of a noncommutative ring...

Manfred Gordon and Edward Martin Wilkinson, Determinants of Petrie matrices.

Alfred Peter Hallstrom, A counterexample to a conjecture on an integral condition for determining peak points (counterexample concerning peak points)........

E. R. Heal and Michael Windham, Finitely generated $F$-algebras with applications to Stein manifolds.

Denton Elwood Hewgill, On the eigenvalues of a second order elliptic operator in an unbounded domain ............................

Charles Royal Johnson, The Hadamard product of $A$ and $A^{*}$.

Darrell Conley Kent and Gary Douglas Richardson, Regular completions of Cauchy spaces.

Alan Greenwell Law and Ann L. McKerracher, Sharpened polynomial approximation

Bruce Stephen Lund, Subalgebras of finite codimension in the algebra of analytic functions on a Riemann surface. .

Robert Wilmer Miller, TTF classes and quasi-generators . .

Roberta Mura and Akbar H. Rhemtulla, Solvable groups in which every maximal partial order is isolated ....

Isaac Namioka, Separate continuity and joint continuity...

Alan Saleski, Entropy of self-homeomorphisms of statistical pseudo-metric

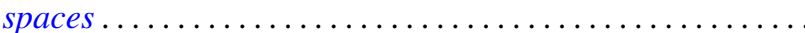

H. A. Seid, Cyclic multiplication operators on $L_{p}$-spaces .....

H. B. Skerry, On matrix maps of entire sequences ............

John Brendan Sullivan, A proof of the finite generation of invariants of a normal

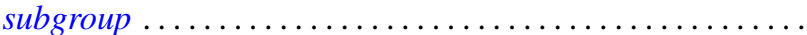

John Griggs Thompson, Nonsolvable finite groups all of whose local subgroups are

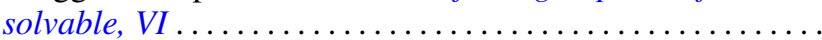

